R. História, São Paulo, 120, p.59-72. jan/jul. 1989.

\title{
O TRÁFICO DE CRIANÇAS ESCRAVAS PARA O BRASIL DURANTE O SÉCULO XVIII*
}

\author{
Horacio Gutiérrez**
}

RESUMO: Estudando listas de escravos transportados do porto de Luanda entre 1734 e 1769 , o autor estima em cerca de $10 \%$ a presença de crianças entre os escravos. Analisa os decretos de impostos de 1758, que discerniam as crias de pé e as crias de peito. Chega a uma média anual de 534 crianças, das quais $73 \%$ seriam crias de pé, declinando o número de crianças na segunda metade do século XVIII. O artigo também analisa as circunstâncias de capturas das crianças e o modo como eram alojadas nos navios, bem como sua taxa de mortalidade na travessia. Procura definir a importância de Luanda com relação a outros portos de Angola e comparar as porcentagens relativas de crianças nos portos do Rio de Janeiro, Bahia e Pernambuco. Finalmente, compara o tráfico brasileiro com o tráfico inglês, dinamarquês $c$ espanhol nas Antilhas, que apresentavam um número bastante superior de crianças.

UNITERMOS: Tráfico de escravos, crias de peito, crias de pé, crianças, portos de origem e de destino.

O tráfico de crianças escravas no período colonial brasileiro não teve a dimensão exorbitante verificada no comércio de escravos adultos, embora nunca tenha deixado de estar presente. Medir e qualificar esse tráfico inaudito comporta amiúde fortes dores de cabeça, visto o sub-registro constante de crianças nas remessas de escravos, pois não pagavam impostos, ou pagavam conforme a idade porcentuais menores que os adultos, o que explica

* Este trabalho originou-se de um seminário de pos-graduaçáo dirigido pelo professor Herbert S. Klein na Universidade de Sao Paulo durante o primeiro semestre de 1986. Os dados utilizados neste artigo encontram-se disponíveis no Data and Program library Service da Universidade de Wisconsin-Madison, Agradecemos ao Professor Klein ter colocado a nossa disposição esta lista de dados, originalmente por ele coletada no Arquivo Histórico Ultramarino de Lisboa. Por outro lado, nem ele nem o DPLS devem ser responsabilizados pela análise e interpretação empreendidas. Uma versão abreviada deste texto foi apresentada no VI Encontro Nacional de Estudos Populacionais da ABEP realizado em Olinda em outubro de 1988.

** Universidade Estadual Paulista/Assis/SP. 
GUTIÉRREZ, Horacio. O tráfico de crianças escravas para o Brasil durante osículo XVIII.

seguramente o relaxamento no controle de seu cômputo por parte dos fiscais encarregados de zelar pelos tributos regios. Conquanto chocante, o comércio de menores teria ocupado um peso diminuto nos volumes registrados durante os três séculos de importação de africanos às terras da América portuguesa. As razões seriam várias: elevado custo dos transportes que tornaria onerosa demais a importação de crianças e bebês dado seu baixo preço de venda; fraca demanda nos mercados brasileiros; e inclusive já foi cogitado ter existido uma certa preocupação de parte das comunidades africanas no sentido de evitar a exportação de crianças ${ }^{1}$. Seja como for, o fato é que os alegados baixos índices de crianças traficadas foram aparentemente uma realidade em certas épocas do comércio negreiro brasileiro, principalmente durante o século dezenove. Contudo, para períodos anteriores a essa data, a importação de crianças parece não ter sido completamente desprezível e em certos momentos pôde ter atingido mesmo níveis equivalentes a $10 \%$ do total dos negros transportados. As estatísticas, infelizmente, são falhas e esparsas, não permitindo generalizações seguras. A intenção deste texto, a partir de um estudo de caso, é mostrar que possivelmente o tráfico de crianças em períodos recuados, primeira metade do século dezoito ou anteriores, pôde ter uma relevância bem superior ao que habitualmente se imagina. E mesmo para períodos posteriores, como veremos, essa hipótese poderia vir a ser aceita se levadas em conta características particulares da documentação. Procurarse-á, em paralelo, situar o tráfico de crianças no contexto global do comércio setecentista brasileiro, fomecendo-se indicações sobre portos de destino, tipo de embarcações utilizadas e sazonalidade do tráfico.

Os dados deste trabalho referem-se ao período que vai de 1734 a 1769 e provêm de registros de navios negreiros saídos de um único porto, Luanda, em Angola, com destino ao Brasil. Até o presente foram descobertos e analisados por historiadores vários destes registros ou listas que relacionam o número de escravos transportados pelo Atlántico, de modo que hoje é possível ter uma noção mais ou menos verossímil dos totais traficados entre 1734 e $180^{2}$ - Nossas informações em particular provêm de listas guardadas no Arquivo Histórico Ultramarino de Lisboa. A virtude singular destas listas, face a outras também disponíveis, é fornecerem não apenas totais globais da

1 CARDOSO, Ciro F.S. Escravismo e dinâmica da população escrava nas Américas, Estudos Econômicas. São Paulo, v.13, n. 1, p. 48, n. 22, 1983.

2 Ag estatísticas publicadas por Maurício Goulart cobrem, sem lacunas, o período 1734-1800. Uma análise crítica dessas e outras estimativas foi realizada por Joseph C. Miller. Cf. GOULART, Maurício. Escravidão Africana no Brasil: Dos Origens à Extinção do Tráfico. São Paulo; Alfa-ômega, 1975,p. 202-209; MILLER, Joseph C., Legal portuguesa slaving from Angola: some preliminary indications of volume and direction, 1760-1830, Revue Française d'Histoire d'Outre-Mer, v. 62, p. 226-227, 1975. 
remessa de crianças e adultos, mas também informações detalhadas sobre a classe de navios que transportavam escravos, o número de embarcações saídas por ano, os portos de destino no Brasil, bem como a data de saída de cada tumbeiro do porto de Luanda. lamentavelmente estas listas registram dados somente para 17 anos dos 36 que conformam o intervalo temporal disponível (1734-69). O período mais prejudicado é a década de 50, que conta com uma única observação. Mesmo assim, os anos aproveitáveis parecem dispor de informações suficientemente consistentes, de molde a permitirem retirar indicações válidas. Outras listas serão utilizadas, sempre que possível, para checar os dados apresentados e preencher as lacunas.

Luanda era o principal entreposto negreiro de Angola no século dezoito, logo seguido pelo de Benguela. Em 1773, a população de Luanda compunha-se de 2.131 pessoas, das quais um contingente considerável eram militares (612 ao todo) e outra parcela expressiva contituía-se de escravos residentes (983 indivíduos) ${ }^{3}$ - A remessa de nativos para o Novo Mundo devia sujeitar-se a vários dispositivos, que regulamentavam a arqueação dos navios, a ordem de saída do porto e os impostos que deviam pagar. Este último assunto, embora essencial para a coroa portuguesa, permaneceu por muito tempo confuso e exposto a pareceres que mudavam de fiscal a fiscal, em decorrência das muitas taxas em vigor e da variação que sofriam conforme a situação analisada. A confusão terminou em 1758 com a publicação de dois alvarás, um dos quais discerne a taxação de crianças escravas. O primeiro deles, de 11 de janeiro, visava revogar a preferência por antigüidade na saída dos navios negreiros de Angola. Isto significa que a partir dessa data as embarcações poderiam zarpar com destino aos portos brasileiros, assim que completassem o carregamento respectivo de escravos (o que às vezes levava meses), mesmo que o número de negros embarcados fosse inferior àquele estipulado na lei das arqueações de 1684 em vigor. A exceção ficava por conta dos navios que transportassem escravos por frete, os quais deviam continuar respeitando o regime de preferência por antigüidade, ou seja, só poderiam sair dos portos de Angola ajustando-se à ordem de seqüência pela qual hav iam entrado, independentemente de algum destes navios completar a sua lotação antes de outro que ingressou mais tarde ${ }^{4}$. O segundo alvará data de 25 de janeiro e tenciona pôr fim à desordem reinante com relação aos direitos de saída e demais taxas que deviam pagar os negreiros em Luanda e nos outros portos de Angola. Abrigadas na falta de critérios uniformes, as fraudes e sonegações vinham sendo, ao que parece, freqüentes. Até a data do alvará as taxas em uso variavam de acordo com o porto de destino dos escravos, mas aparentemente independiam do sexo ou idade do negro resgata-

3 KLEIN, Herberts.. The Middle Passage: Com;mmtive Studies in the Atlantic Stave Trade Princeton; Princeton University Press, 1978. p. 41-42.

4 GOULART, Maurício, op. cit., p. 192-193. 
GUTIÉRREZ, Horacio. O tráfico de Crianças escravas para o Brasil durante o século XVIII

do. A disposição de 1758 estabelece novas taxas e critérios. De agora em diante dever-se-ia pagar um imposto de $8 \$ 700$ - além de $\$ 300$ de subsidio por cada escravo que excedesse quatro palmos de altura (um metro mais ou menos), seja homem ou mulher. Quanto às crianças, o alvará distingue duas categorias. Por um lado, as crianças que já caminhavam e que mediam até quatro palmos; denominadas crias de pé, teriam abatimento de $50 \%$, isto é, deviam pagar cada uma direitos equivalentes a $4 \$ 350$ mais $\$ 150$ de subsídios. A segunda categoria contemplava as crias de peito que estariam "livres de todo e qualquer imposto, fazendo uma só cabeça com suas respectivas mães" 5 . O novo sistema de tributação começara a vigorar a partir de $1760 \mathrm{e}$ teve ao menos três conseqüências infelizes para os historiadores: primeiro, diminuíra o rigor do cômputo dos bebês de colo, pois seu registro era indiferente para as finalidades da tributação; segundo, reduz-se a incidência das crias de pé, talvez confundidas, intencionalmente ou não, com adultos; terceiro, as crianças de pleno direito, isto é, com mais de quatro palmos de altura, ora figurariam separadamente, ora começariam a aparecer na lista dos adultos sem possibilidade de serem identificadas.

Quantas crianças ingressaram no Brasil durante o século dezoito? Entre 1734 e 1769, segundo os registros consultados, 9.220 crianças foram transportadas desde Luanda para o Brasil, sem incluir no cômputo as crianças de pleno direito nem os anos para os quais o registro é lacunoso (ver tabela 1). Em média, 542 menores foram exportados anualmente para o Brasil, o que não deixa de ser uma cifra significativa. Se supormos que essa média é válida também para os anos para os quais não contamos com dados das décadas de 1731-1770, o total de crias de peito e de pé comercializadas nessa rota elevar-se-ia a 21.680 menores nesses quarenta anos. Desse total, $76 \%$ corresponderia a crias de pé e o restante a bebês de colo. Os números, sem dúvida, ressaltam pelo seu elevado montante absoluto. Note-se, além do mais, que correspondem apenas à rota de Luanda. O momento da importação coincide no Brasil com o auge da mineração do ouro e do diamante, para onde o afluxo de escravos africanos era constante. Para se ter uma idéia do que significaria a importação anual de 542 crianças, basta lembrar que no Serro do Frio, uma expressiva comarca mincradora da época, o senhor de maior porte contava em 1738 corn 79 escravos e o total de senhores de escravos na região alcançava nesse mesmo ano a 1.744 pessoas ${ }^{6}{ }_{-}$

Qual foi a importância relativa das crianças no conjunto de africanos importados? Sem contrapesa, os adultos representaram a maior parcela das pessoas negociadas. Frente à média de 542 crianças saídas anualmente de Luanda, a média de adultos situou-se em torno de 7.919 negros levando-se

5 Geulart, ibidem, p. 192-197.

6 LUNA, Francisco Vidal. Minas Gerais: Escravos e Senhores (1718-1804). São Paulo; IPE, 1981. p. 201. 
R.Historia, São Paulo, 120, p 59-72 Jan/jul. 1989.

Tabela 1 - Tráfico mínimo ${ }^{a}$ de crianças escravas de Luanda para o Brasil, 1734-69

\begin{tabular}{|c|c|c|c|c|c|c|c|}
\hline Anos & $\begin{array}{c}\text { Crias } \\
\text { de } \\
\text { peito }\end{array}$ & $\begin{array}{c}\text { Crias } \\
\text { de } \\
\text { pé }\end{array}$ & $\begin{array}{c}\text { Total } \\
\text { crianças }\end{array}$ & $\begin{array}{c}\text { Total } \\
\text { crianças } \\
+ \text { +adultos }^{\mathrm{b}}\end{array}$ & $\begin{array}{c}\% \\
\text { crianças }\end{array}$ & $\begin{array}{l}\text { Número } \\
\text { de embar- } \\
\text { caçöes c/ } \\
\text { crianças }\end{array}$ & $\begin{array}{c}\text { Total de } \\
\text { embarca- } \\
\text { çбes } \\
\text { negreiras }\end{array}$ \\
\hline 1734 & $(339) \mathrm{c}$ & $(1.057) \mathrm{c}$ & 1.396 & 10.109 & 13,8 & 25 & 25 \\
\hline 1738 & $(289) \mathrm{c}$ & $(898) c$ & 1.187 & 8.810 & 13,5 & 19 & 19 \\
\hline 1740 & 98 & 311 & 409 & 8.484 & 4,8 & 22 & 22 \\
\hline 1741 & 154 & 736 & 890 & 9.158 & 9,7 & 23 & 23 \\
\hline 1742 & 135 & 249 & 384 & 10.249 & 3,7 & 23 & 24 \\
\hline 1744 & 166 & 426 & 592 & 8.848 & 6,7 & 20 & 20 \\
\hline 1747 & 99 & 1.442 & 1.541 & 9.869 & 15,6 & 25 & 25 \\
\hline 1748 & 101 & 894 & 995 & 11.558 & 8,6 & 29 & 30 \\
\hline 1749 & 99 & 782 & 881 & 9.776 & 9,0 & 25 & 25 \\
\hline Subtotal & 1.480 & 6.795 & 8.275 & 86.861 & 9,5 & 211 & 213 \\
\hline $\bar{x}$ anual & 164 & 755 & 919 & 9.651 & & 23 & 24 \\
\hline 1758 & $(108) c$ & $(31) c$ & 139 & 8.856 & 1,6 & 21 & 24 \\
\hline 1762 & 80 & 22 & 102 & 7.540 & 1,4 & 19 & 22 \\
\hline 1763 & 61 & 17 & 78 & 4.688 & 1,7 & 14 & 21 \\
\hline 1764 & 76 & 18 & 94 & 7.159 & 1,3 & 16 & 18 \\
\hline 1765 & 200 & 62 & 262 & 10.431 & 2,5 & 26 & 27 \\
\hline 1766 & 97 & 14 & 111 & 6.712 & 1,7 & 18 & 25 \\
\hline 1767 & 69 & 8 & 77 & 6.491 & 1,2 & 19 & 26 \\
\hline 1769 & 46 & 36 & 82 & 5.110 & 1,6 & 15 & 17 \\
\hline Subtotal & 734 & 208 & 945 & 56.987 & 1,7 & 148 & 180 \\
\hline$\overline{\mathrm{x}}$ anual & 92 & 26 & 118 & 7.123 & & 19 & 23 \\
\hline Total & 2.217 & 7.003 & 9.220 & 143.848 & 6,4 & 359 & 393 \\
\hline $\bar{x}$ anual & 130 & 412 & 542 & 8.462 & & 21 & 23 \\
\hline
\end{tabular}

Notas: a. O tráfico é mínimo pois não foram consideradas as crianças que pagavam imposto completo, em virtude de sua indicação inconstante nas fontes (às vezes as discriminavam e outras eram somadas aos adultos).

b. Os escravos adultos desta coluna referem-se apenas àqueles que integravam embarcações nas quais também estavam sendo transportadas crianças.

c. Os registros de Luanda não diferenciavam crianças da peito e de pé para os anos 1734, 1738 e 1758, indicando unicamente o total de crianças transportadas. Os valores entre parênteses foram estimados aplicando-se às crianças de peito e de pé o porcentual médio de cada tipo de criança verificado nos 4 anos seguintes aos anos calculados.

Fonte: Arquivo Histórico Ultramarino (Lisboa): Angola, caixas 16-25, 27, 29-33 e maço 9 . 
GUTIÉRREZ, Horacio. O tráfico de crianças escravas para o Brasil durante o século XVIII

em conta apenas os 359 navios que transportavam crianças, ou então 8634 adultos computando-se todas as 393 embarcações negreiras aqui estudadas,

É sabido que a economia escravista demandava especialmente africanos jovens $\mathrm{cm}$ idade produtiva para compor, sem demora, os plantéis necessários à extração dos metais preciosos ou à produção dos artigos de exportação. No limite, o plantel ideal era aquele integrado por escravos adultos voltados integralinente ao processo produtivo e que pudessem repor para seu proprietário, no menor tempo possível, o custo inicial de sua compra e as despesas fixas de sua manutenção. Como explicar, nesse contexto, que nada menos do que $6,4 \%$ dos carregamentos de escravos tenham sido compostos de crianças, escravos improdutivos por definição, e ainda mais, que tenham encontrado demanda nos mercados brasileiros? Deixa de ser parco, assim visto, o valor de $6,4 \%$ de crianças transportadas e, pelo contrário, cobra sentido buscar uma explicação à sua presença. O percentual não só fica longe de ser irrisório, como suscita a pergunta contrária: por que tantas crianças no tráfico escravista? Acrescem ao fenômeno outros eventos que alimentam a questão: do total de 23 embarcações zarpadas em média anualmente de Luanda com negros escravizados, 21 navios transportavam crianças. Ou seja, praticamente todos, se lembrarmos que podia ocorrer omissão no cómputo dos menores.

Um aspecto, entretanto, parece claro da leitura dos dados da tabela 1: o peso das crianças no tráfico não foi homogêneo ao longo do período em exame. O percentual de menores exportados de Luanda decresce no decorrer do século dezoito, sendo que nas décadas anteriores a 1750 atinge cifras consideráveis: 9,5\% dos carregamentos eram compostos de crianças, ao passo que nos anos situados na segunda metade do século, o percentual cai para apenas $1,7 \%$. Com relação ao número de navios com crianças, os dados também apontam nessa direção: nos anos anteriores a 1750, do total de 213 tumbeiros registrados, 211 transportavam crianças, enquanto após essa data, a correlação é de 180 navios registrados, dos quais somente 148 com menores a bordo. Infelizmente, não é possível saber se apenas a mudança das regras tributárias anteriormente comentadas foi que quebrou a tendência, ou se há também, o que não seria improvável, outros fatores em jogo que teriam flexionado a curva para baixo. O que se constata, de qualquer forma, é uma queda violenta, ocorrida nas quatro ultimas décadas do século, do número de crias de pé transportadas. Nas primeiras décadas do século dezenove, conforme dados de Klein, o afluxo de crianças cativas de todos os tipos continuaria não indo além do patamar de $2 \%$, pelo menos dentre os carregamentos que aportaram no Rio de Janeiro ${ }^{7}$

Será que o tráfico de Luanda pode ser considerada um protótipo das importações de escravos do Brasil setecemista? A julgar pelo desempenho de Luanda no contexto global do comércio negreiro português na África de então, sem dúvida seu caso é inportante As estimativas mais confiáveis e pre-

7 KLEIN. Herbert S, op. cit., p. 57-58. 
R. Historia, São Paulo, 120, p59-72, jan/jul. 1989.

cisas para o tráfico do século dezoito continuam sendo as de Maurício Goulart, aprimoradas com novas evidências de arquivo encontradas por David Birmingham, Herbert Klein e Joseph Miller no que se refere à região de Angola. De acordo com documentos divulgados por Goulart, em termos de exportação de escravos, o porto de Luanda contribuiu com $60 \%$ dos negros expedidos da região de Angola para o Brasil entre 1760 e $1800^{8}$. Os $40 \%$ restantes ficaram por conta de Benguela (a contribuição de Cabinda e Ambriz neste período é desconhecida, mas aparentemente não foi significativa). Por outro lado, desde os inícios do século dezoito, Angola começa progressivamente a sobrepujar a outra área de relevância para o tráfico brasileiro desse momento, a Costa da Mina. De sorte que se nas primeiras décadas de $1700,50 \%$ dos escravos remetidos ao Brasil eram comprados ou adquiridos em Angola, já no final do século a cifra havia aumentado para $75 \%$. Conforme cálculos atualizados, o Brasil importou de Angola 1.285.900 escravos durante o século dezoito (a estimativa de Goulart é de 1,140.000), contra 605.500 da Costa da Mina ${ }^{9}$.

A porcentagem de crianças traficadas nas outras rotas que não Luanda, pode ser parcialmente conhecida. Segundo uma Relação de escravos disponível no Instituto Histórico e Geográfico do Rio de Janeiro e analizada por Goulart, dos 240.520 escravos exportados pelo porto de Benguela entre 1760 e 1800, somente 446 eram crias de meio direito (crias de pé), ou seja, $0,2 \%$ do total. A referida relação é um documento que foi elaborado com vistas a apurar o pagamento dos novos impostos que decorriam do alvará de 1758. Nesse sentido, contabiliza apenas os escravos e navios passíveis de tributação ${ }^{10}$. Outra indicação fragmentária do tráfico de crianças em Benguela é fornecido por estatísticas coletadas por Klein em arquivos portugueses. Uma amostra de cinco navios carregados em Benguela em 1738 acusa a presença de 278 crianças e bebês a bordo, ou $15,5 \%$ da lotação de escravos. Porém, os dados disponíveis para algumas décadas depois revelam outros valores. Entre 1762 e 1767, registra-se a saída de 83 tumbeiros de Benguela e em conjunto as crianças perfazem $1,2 \%$ do total de escravos transportados ${ }^{11}$, O padrão de Benguela, aparentemente, foi muito similar ao de Luanda. Antônio Carreira fornece ainda dados adicionais para outras rotas. A Companhia de Pernambuco e Paraíba, que teve o monopólio do tráfico para essas duas regiões entre 1759 e 1784, transportou em seus navios que aportaram em Angola 480 crias (1\% do total de escravos ali comprados); por outro lado, nas embarcações zarpadas da Costa da Mina, a proporção de crias

8 Maurício Goulart, op. cit., p. 202-209.

9 KLEIN, Herbert S.. A demografía do tráfico atlântico de escravos para o Brasil, Estudos Econômicos, São Paulo, v. 17, n. 2, p, 135, 1987, Para dados completos e detalhados sobre volumes do tráfico para o Brasil no século dezoito, consultar ademais GOULART, Maurício, op. cit.; MILlER, Joseph C. op. cit.; e KLEIN, Herbert S.. The Middle Passage

10 Ibidem, p. 206.

11 KLEIN, Herbert S. . he Middle Passage. p. 255-256. 
GUTIÉRREZ, Horacio. O tráfico de crianças escravas para o Brasil durante o século XVIII.

adquiridas foi análogo (590 que perfaziam também $1 \%$ do total de negros resgatados na região). A outra grande Companhia da época, a de Grão-Pará e Maranhão, registra em seus livros o transporte de um número muitíssimo mais expressivo de menores: 19,6\% dos totais enviados ao Brasil entre 1756 e 1788. Convém salientar, no entanto, que esta cifra contempla crias de peito (pouquíssimas) c principalmente adolescentes ("rapaz", "moleque", "rapariga" etc), que quiçás, nas listas anteriormente vistas, foram incluídos entre os adultos ${ }^{12}$. Aliás, esta ambigüidade (ou omissão) na especificação das crias de peito e das crias de pé e de pleno direito nos registros posteriores a 1760, parece acenar para algo substancial na explicação do declínio do tráfico de crianças. Urna anáiise mais fina deveria dispor, entretanto, de outros elementos como, por exemplo, parâmetros de preços de crianças ao longo dos século dezoito e dezenove. De qualquer maneira, é sugestiva a seguinte informação: em 1799 um almanaque do Rio de Janeiro atribuiu à capital da colônia uma população escrava de 14.986 pessoas, das quais 3.181 , ou seja $21,2 \%$, eram crianças com até sete anos de idade, incluindo-se no cômputo os recém-nascidos ${ }^{13}$. A essa altura, como sabido, o Rio de Janeiro já se tinha tornado o principal porto brasileiro de importação de africanos.

Tabela 2 - Número de crianças nas embarcações, 1734-69

\begin{tabular}{crrrrr}
\hline $\begin{array}{c}\text { Tamanho dos } \\
\text { lotes de } \\
\text { crianças }\end{array}$ & \multicolumn{2}{c}{ Embarcaçöes } & \multicolumn{2}{c}{ Crianças } & $\begin{array}{c}\text { No médio de } \\
\text { crianças por } \\
\text { embarcação }\end{array}$ \\
\cline { 2 - 5 } & $\mathrm{n}^{\mathrm{Q}}$ & $\%$ & $\mathrm{n}^{\mathrm{O}}$ & $\%$ & 5 \\
$11-10$ & 152 & 41,9 & 746 & 7,9 & 15 \\
$21-40$ & 72 & 19,8 & 1.057 & 11,2 & 29 \\
$41-60$ & 48 & 13,2 & 1.371 & 14,5 & 79 \\
$61-100$ & 42 & 11,6 & 2.053 & 21,7 & 129 \\
$101-182$ & 39 & 10,7 & 2.939 & 31,1 & 13,5 \\
\hline Total & 10 & 2,8 & 1.285 & 13,5 & 126 \\
\hline
\end{tabular}

Observação: Além đas crias đe peito e đe pé computaram-se nesta tabela tambêm as crianças de pleno direito (que pagavam imposto completo) e que aparecem relacionadas nas fontes unicamente para algumas embarcações nos anos 1762-67, De fato, trata-se de 231 crianças que figuram no registro de 31 embarcações, quatro das quais não transportavam crias de peito nem de pé, mas apenas crianças de pleno direito e adultos. Isto explica a leve discrepância nos totais desta tabela em relação à tabela 1. Esta observação é válida também para a tabela 4 .

Ponte: Idem, tabela 1.

12 CARREIRA, Antônio. As Companhias Pombalinas. Lisboa; Presença, 1983. p. 90 e 248 .

13 NUNES, Antonio Duarte, Almanac histórico tia cidade de S, Sebastião do Rio de Janeiro, Revista do instituto Histórico e Geográfico Brasileiro. Rio de Janeiro, v. $21, \mathrm{n} .176,1858$. 
R. História, São Paulo, 120, p.59-72, jan/jul, 1989.

Como c em que condições eram transportadas as crianças africanas para o Brasil? Em Luanda, as embarcações que traficavam com menores possuíam as mais variadas arqueações e variava também o número de crianças lançadas a bordo. O número mais comum era transportar entre uma e dez crias (ver tabela 2), Nesta categoria estavam 41,9\% dos tumbeiros da amostra analisada neste trabalho. Quase um terço dos menores que chegaram ao Brasil, contudo, viajara em navios que transportaram entre 61 e 100 crianças simultaneamente. Houve tumbeiros, inclusive, que numa única viagem embarcaram 150 ou 180 meninos e meninas de sorte que estes chegaram a representar mais de $20 \%$ do total de escravos a bordo (ver tabela 3). Estes casos são constatados apenas durante a primeira metade do século dezoito.

Tabela 3 - Os 10 maiores tumbeiros de crianças no perfodo 1734 a 1769

\begin{tabular}{|c|c|c|c|c|c|c|c|}
\hline \multirow{2}{*}{$\begin{array}{c}\text { Tipo } \\
\text { de } \\
\text { embarcação }\end{array}$} & \multirow{2}{*}{$\begin{array}{l}\text { Ano da } \\
\text { viagem }\end{array}$} & \multirow{2}{*}{$\begin{array}{l}\text { Porto de } \\
\text { destino }\end{array}$} & \multicolumn{3}{|c|}{ № crianças transportadas } & \multirow{2}{*}{$\begin{array}{c}\text { Total } \\
\text { - crianças } \\
+ \text { adultos }\end{array}$} & \multirow{2}{*}{$\begin{array}{c}\% \\
\text { criança }\end{array}$} \\
\hline & & & $\begin{array}{c}\text { Crias } \\
\text { de peito }\end{array}$ & $\begin{array}{l}\text { Crias } \\
\text { de pe }\end{array}$ & Total & & \\
\hline Navio & 1734 & Rio de Janeiro & s.i. & s.i. & 182 & 694 & 26,2 \\
\hline Navio & 1734 & Pernambuco & s.i. & s.i. & 117 & 526 & 22,2 \\
\hline Corsário & 1738 & Rio de Janeiro & s.i. & s.i. & 112 & 778 & 14,4 \\
\hline Galera & 1741 & Rio de Janeiro & 9 & 127 & 136 & 529 & 25,7 \\
\hline Galera & 1741 & Rio de Janeiro & 12 & 115 & 127 & 559 & 22,7 \\
\hline Penque & 1747 & Rio de Janeiro & 0 & 113 & 113 & 484 & 23,3 \\
\hline Galera & 1747 & Bahia & 12 & 108 & 120 & 500 & 24,0 \\
\hline Penque & 1747 & Rio de Janeiro & 3 & 105 & 108 & 510 & 21,2 \\
\hline Galera & 1749 & Bahia & 11 & 140 & 151 & 741 & 20,4 \\
\hline Corveta & 1749 & Santos & 9 & 110 & 119 & 593 & 20,1 \\
\hline
\end{tabular}

s.i. $=$ sem informação.

Fonte: Idem, tabela 1.

A captura dos menores e dos adultos em Angola podia ocorrer de diversos modos;. Numa Memória escrita e apresentada à Real Academia de Ciências de Lisboa em 1793, Luiz Antônio de Oliveira Mendes critica acremente a maneira cruel pela qual seus compatriotas se compraziam em capturar negros na África. Nas sociedades locais existiam algumas formas aceitas 
GUTIÉRREZ, Horacio. O tráfico de crianças escravas para o Brasil durante o século XVIII.

de escravidão advindas por adultério ou roubo e que os nativos praticavam desde tempos remotos. As formas ilegais e condenáveis consistiam na captura pela força, recorrendo a calúnias ou por aleivosia ${ }^{14}$. Organizavam-se investidas que cobriam raios de até cem léguas dos portos de embarque e nas quais eram aprisionados homens, mulheres e crianças. Reduzidos, os negros deviam percorrer vastas regiões interioranas para chegar ao litoral; outros aportavam por mar capturados em pontos costeiros adjacentes. Osfunidores, diz Oliveira Mendes, procediam então a permutarem escravos por tabaco, missangas, pólvora, fazendas ou instrumentos de ferro com os quais mantinham atados os prisioneiros. O libambo, uma sólida corrente de ferro, prendia pela mão direita várias dezenas de escravos simultaneamente. As mulheres eram presas a libambos diferentes da dos homens, enquanto as crianças ficavam soltas perto de suas mães ${ }^{15}$. Normalmente nos portos de embarque procedia-se ao batismo católico dos escravos e à marcação com ferro quente daqueles que, para sua infelicidade, já possuíam dono no Brasil por terem sido encomendados. A bordo dos navios, homens e mulheres ocupavam compartimentos diferentes, sendo que os menores e as grávidas ficavam alojados, geralmente, num pavimento exclusivo ${ }^{16}$. Walsh, no início do século dezenove, observou um navio português recém capturado pela marinha inglesa e relata que os homens ficavam comprimidos num compartimento junto com as crianças de sexo masculino. Às mulheres reservava-se-lhes cubículos aparte em companhia das grávidas e das meninas ${ }^{17}$.

Muitos cronistas ficaram particularmente impressionados com a superlotação dos navios, A lei das arqueações de 1684 regulamentou este aspecto estabelecendo limites à lotação permitida. A lei mandava regular também as quantidades mínimas de água e comida que os navios deviam providenciar antes de sua partida. Aparentemente os abusos diminuíram no correr do século dezoito e nem sempre a superlotação se verificava. Pesquisa de Klein mostra que entre 1762 e 1765 os navios que saíram de Luanda zarparam, em média, com $95 \%$ da capacidade legal permitida. Era mais freqüente os navios pequenos navegarem mais lotados do que os de maior tonelagem ${ }^{18}$. A questão da superlotação tem sido apontada repetidamente na historiografia como uma das causas importantes da alta mortalidade na travessia do Atlântico. Ela teria sido estimulada pela ânsia desenfreada de lucro por parte dos

14 MENDES, Luiz Antônio de Oliveira, Memória a Respeito dos Escravos e Tráfico da Escravatura entre a Costa d África e o Brasil. Porto; Escorpião, 1977. p. 39-

15 Ibidem, p. 43-47.

16 SALVADOR, José Gonçalves. Os Magnatas do Tráfico Negreiro: Séculos XVI e XVIII. São Paulo: Pioneira/Edusp, 1981. p.96-101.

17 WALSH, Robert. Notícias do Brasil (1828-1829). São Paulo- Itatiaia/Edusp 1985, vol. II.p. 212-217.

18 KLEIN, Herbert S., The Middle Passage, p. 30. 
capitães das embarcações. Contudo, correlações feitas entre o númer de escravos embarcados nos navios e a taxa de mortalidade a bordo não confirmam essa hipótese. Além do mais, a superlotação, como regra, não teria existido. A mortalidade relacionava-se mais com outros fatores, como $\mathrm{O}$ tempo de duração da viagem marítima entre o porto de saída do navio na África e o de chegada no Brasil. Ou então a estação do ano escolhida para iniciar a travessia. Uma amostra de navios aportados no Rio de Janeiro entre 1795 e 1811 revela que a mortalidade a bordo dos escravos oriundos de Luanda era de 103 para cada mil embarcados (ou 10,3\%), ao passo que os que provinham de Moçambique morriam numa proporção de 234 por mil $(23,4 \%)$, O tempo médio da viagem de Luanda até o Rio de Janeiro era de 34 dias; já de Moçambique a travessia prolongava-se por um tempo médio de 64 dias consecutivos $^{19}$. Não havia uma diferença nítida entre taxas de mortalidade adulta e infantil, mas aparentemente as crianças tinham uma maior resistência durante as viagens ${ }^{20}$.

Comentaremos brevemente, para finalizar, os portos de destino no Brasil das crianças escravas exportadas de Luanda. O padrão detectado acompa-

Tabela 4 - Portos de destino das crianças escravas, 1734-69

\begin{tabular}{lcccc}
\hline Portos brasileiros & № crianças & $\%$ & $\begin{array}{c}\text { Número de } \\
\text { embarcaçōes } \\
\text { com crianças }\end{array}$ & $\begin{array}{c}\text { Total de } \\
\text { embarcaçóes } \\
\text { negreiras }\end{array}$ \\
\hline Portos do Leste & 9.065 & 95,9 & 349 & 379 \\
Rio de Janeiro & 5.108 & 54,0 & 193 & 206 \\
Bahia & 2.780 & 29,4 & 93 & 95 \\
Pernambuco & 1.177 & 12,5 & 63 & 78 \\
Portos do Sul & 324 & 3,4 & 5 & 5 \\
Colônia do Sacramento & 205 & 2,2 & 4 & 4 \\
Santos & 119 & 1,2 & 1 & 1 \\
Portos do Norte & 62 & 0,7 & 9 & 9 \\
Maranhẩo & 36 & 0,4 & 5 & 4 \\
Pará & 26 & 0,3 & 4 & 393 \\
\hline Total & 9.451 & 100,0 & 363 & \\
\hline Fon & & & & \\
\hline
\end{tabular}

Fonte: Idem tabela 1.

19 Esses tempos médios de viagem foram calculados a partir de uma amostra de navios aportados no Rio de Janeiro entre 1825-30. A mortalidade a bordo parece ter diminuído nestes anos: a média dos escravos vindos de Luanda caiu para 71 por mil enquanto os de Moçambique registraram o índice de 145 por mil. Cf. KLEIN, Herbert S. . The Middle Passages p. 73-94.

20 Ibidem, p. 37 e 51-94. 
GUTIÉRREZ, Horacio. O tráfico de criança» escravas para o Brasil durante o século XVIII.

nha, evidentemente, aquele verificado no tráfico de adultos, ao qual estava vinculado. O principal porto de desembarque foi o Rio de Janeiro (ver tabela 4). Do total de 9.451 crianças registradas na amostra de 1734-69, 54\% tiveram como ponto final da travessia atlântica o porto do Rio. Em segundo e terceiro lugares ficaram colocados os outros dois principais escoadouros de escravos, Bahia e Pernambuco, com participações de 29,4 e 12,5\% respectivamente. Outros portos, do sul ou norte do país, revelam expressividade fraca. As saídas de embarcações de Luanda ocorriam com maior freqüência nos meses de inverno e primavera (julho a dezembro), mas não há um pico definido e nos restantes meses do ano igualmente o trânsito de navios negreiros era intenso. Os mercados de escravos nos portos brasileiros operavam o ano corrido recebendo e acondicionando, como podiam, os adultos e crianças que chegavam. O espectáculo medonho dos mercados escravistas foi descrito periodicamente por viajantes, sobretudo as vicissitudes que envolviam os mais famosos, como o de Valongo, no Rio de Janeiro. Os observadores ficavam estarrecidos. ${ }^{25}$

As características do tráfico de crianças escravas que apresentamos não são exclusivas do tráfico português. Encontram paralelos - e diferenças com as outras grandes rotas que cruzavam o Atlântico em direção ao Novo Mundo. Mas evitamos fazer comparações porque a base documental a este respeito é altamente traiçoeira. A imprecisão e profusão de termos para designar os bebês, crianças e adolescentes nas distintas áreas americanas, praticamente distorce de partida qualquer tentativa de comparação minimamente satisfatória. A complicação surge já na definição do que fosse uma criança, conceito que não necessariamente era igual na África, no Caribe ou no Brasil, sem contar que não existiam entre os africanos atestados de nascimento, ou coisa parecida, que permitam aos historiadores comparar, rigorosamente, grupos de pessoas de uma mesma faixa etária. Os dados disponíveis, de qualquer maneira, são interessantes como referencial. Assim, por exemplo, a partir de uma amostra de navios negreiros que operaram no Caribe inglês entre 1791-98, pode constatar-se que o percentual de crianças ("children" sem maiores especificações) alcançara a $14 \%$ do total de escravos trazidos da região de Congo-Angola. Por outro lado, nas embarcações destinadas ao Caribe dinamarquês esse índice aumentava para 17,9\% (amostra de 49 navios que navegaram entre 1777 e 1789), ao passo que no Caribe holandês chegava a $21,7 \%$ (amostra para o período 1730-1795). O caso mais

21 CONRAD, Robert E. sumariza esses relatos de viajantes em livro recente. Ver sua obra Tumbeiros: O Tráfico de Escravos para o Brasil. Sâo Paulo: Brasiüense, 1985. p. 57-63. 
R. História, São Paulo, 120. p.59-72, jan/jul. 1989.

notável é Cuba que registra para as décadas de 1790-1820 urna porcentagem de crianças nos carregamentos de escravos que atinge $43 \%$ do total. Mas neste caso é possível saber que na contagem foram incluídos muleques $e$ malecones de entre 7 e $17 \operatorname{anos}^{22}$. Face a estes índices, evidentemente o tráfico brasileiro de crianças revela-se atípico. Novamente, então, faz-se necessário ponderar a Fidelidade de registro das fontes portuguesas, além de sublinhar o terreno escorregadio em que se assenta este tipo de documentação.

ABSTRACT: The author analyses lists of slaves imported from Luanda between 1734 and 1769 , estimating the presence of $10 \%$ of children in the slave trafic to Brazil. Perusing tax decrees of 1758, notices that different amounts of taxes were payed by "crias de pé" and children still in their mothers lap. The author establishes an annual rate of 534 children, that declined after the middle of the 18th century. The article also describes the manner they were captured in the African coast, their lodgement on board the slave ships, their rate of mortality; compares Luanda to other Angolan and Brazilian ports. Finally, the author compares the brazilian trade in slave children to the higher numbers registered for the British, Dutch and Spanish trade in the Caribbean region.

UNITERMS: Slave trade, slave children, origin and destination ports.

\section{REFERÊNCIAS BIBLIOGRÁFICAS}

CARDOSO,Ciro Flamarion S.

1983 "Escravismo e dinâmica da população escrava nas Américas", Estudos Econômicos, São Paulo, v. 13, n. 1, p. 41-53.

CARREIRA, Antônio

1983 As Companhias Pombalinas. Lisboa: Presença, $2^{\circ}$ ed. revista.

CONRAD, Robert E.

1985 Tumbeiros: O Tráfico de Escravos para o Brasil. São Paulo: Brasiliense.

\section{GOULART, Mauricio}

1975 Escravidão Africana no Brasil: Das Origens à Extinção do Tráfico. 3- ed. revista. São Paulo: Alfa-ômega,.

22 KLEIN, Herbert S. . African women in the Atlantic Slave Trade, in C.C. Robertson e M.A. Klein (org.). Women and Slavery in Africa. Madison; The University of Wisconsin Press, 1983. 
GUTIÉRREZ, Horacio. O tráfico de crianças escravas para o Brasil durante o século XVIII.

KLEIN, Herbert S.

1978 The Middle Passage: Comparative Studies in the Atlantic Slave Trade. Princeton: Princeton University Press.

1983 African women in the Atlantic Slave Trade, in C.C. Robertson e M.A. Klein (org.), Women and Slavery in Africa, Madison: The University of Wisconsin Press, p. 29-38.

1987 "A demografía do tráfico atlântico de escravos para o Brasil", Estudos Econômicos, São Paulo, v. 17, n. 2, p. 129-49.

LUNA, Francisco Vidal

1981 Minas Gerais: Escravos e Senhores (1718-1804). São Paulo: 1PE.

MENDES, Luiz Antônio de Oliveira

1977 Memória a Respeito dos Escravos e Tráfico da Escravatura entre a Costa $d$ África e o Brasil. Porto; Escorpião.

MILLER, Joseph C.

1975 Legal Portuguese slaving from Angola: some preliminary indications of volume and direction, 1760-1830 , Revue Française d'Histoire d' OutreMer, v. 62, n. 226-227, p. 135-76.

NUNES, Antonio Duarte

1858 Almanach histórico da cidade de S. Sebastião do Rio de Janeiro , Revista do Instituto Histórico e Geográfico Brasileiro, Rio de Janeiro, tomo 21, p. $5-176$.

SALVADOR, José Gonçalves

1981 Os Magnatas do Tráfico Negreiro: Séculos XVI e XVII. São Paulo: Pioneira/Edusp.

WALSH, Robert

1985 Notícias do Brasil (1828-1829). São Paulo: Itatiaia/Edusp, 2 volumes. 